\title{
Efecto de la harina de camu camu sobre el daño hepático inducido por acetaminofén en ratones
}

\section{Effect of camu camu flour on acetaminophen-induced liver damage in mice}

\author{
Katia Santa Cruz-Vega ${ }^{1, a}$, Oscar Huamán-Gutiérrez ${ }^{2, b}$ \\ ${ }^{1}$ Escuela Profesional de Nutrición, Facultad de Medicina, Universidad Nacional Mayor de San Marcos. Lima, Perú. \\ ${ }^{2}$ Centro de Investigación de Bioquímica y Nutrición, Facultad de Medicina, Universidad Nacional Mayor de San Marcos. Lima, Perú. \\ ${ }^{a}$ Licenciado en nutrición, ORCID: https://orcid.org/0000-0001-9271-3910 \\ ${ }^{\mathrm{b}}$ Magister en bioquimica, doctor en ciencias de la salud. ORCID: https://orcid.org/0000-0002-6224-9165
}

\section{Correspondencia:}

Katia Santa Cruz Vega

katia.santacruz@unmsm.edu.pe

Recibido: 3 de diciembre 2020

Aprobado: 12 de junio 2021

Publicación en línea: 15 de julio 2021

Conflictos de interés: Los autores declaran no tener conflictos de interés.

Fuente de financiamiento: Vicerrectorado de Investigación y Posgrado, Universidad Nacional Mayor de San Marcos, RR 05969-R-18

El presente estudio forma parte de la tesis de Katia Lizet Santa Cruz Vega: "Efecto de la administración de la harina de Myrciaria dubia (camu camu) sobre daño hepático inducido por paracetamol en ratones". Tesis para optar el Título Profesional de Licenciada en Nutrición de la Facultad de Medicina, Universidad Nacional Mayor de San Marcos, Lima, Perú.

Citar como: Santa-Cruz K, HuamánGutiérrez O. Efecto de la harina de camu camu sobre el daño hepático inducido por acetaminofén en ratones. An Fac med. 2021;82(2):140-5. DOI: https:/doi. org/10.15381/anales.v82i2.18411
Resumen

Objetivos. Evaluar el efecto de la harina de Myrciaria dubia (camu camu) sobre el tejido hepático inducido a toxicidad por acetaminofén en ratones. Métodos. Diseño experimental. Se preparó una suspensión de harina de camu camu (HCC) con almidón al 1,6\%. Se emplearon 40 ratones machos de la cepa BALB/c, con un peso promedio de 30,8 $\mathrm{g}$ y de dos meses de edad, los cuales fueron divididos en cinco grupos, recibiendo el siguiente tratamiento, vía orogástrica, por un período de 10 días, grupos I y II: almidón 1,6\% $10 \mathrm{~mL} / \mathrm{kg}$; grupo III: HCC $200 \mathrm{mg} / \mathrm{kg}$, grupo IV: HCC $500 \mathrm{mg} / \mathrm{kg}$ y grupo V: HCC $800 \mathrm{mg} / \mathrm{kg}$. Al $6^{\text {to }}$ dia de tratamiento se le administró acetaminofén $\left(300 \mathrm{mg} / \mathrm{kg}\right.$ ) a los grupos $I I-V$ hasta el $10^{\mathrm{mo}}$ día. Terminada la intervención los animales fueron puestos en ayunas de 12 horas, para luego ser sacrificados previa anestesia con pentobarbital sódico. Se extrajo el hígado, se identificó y seccionó el lóbulo mayor para el estudio bioquímico e histológico. Resultados. La harina de camu camu redujo los niveles del índice hepático, y presentó un mejor perfil del sistema glutatión, comparado con el grupo II; sin embargo, las cifras de lipoperoxidación no mostraron diferencia significativa. A nivel histológico, en los grupos que recibieron HCC se observaron hepatocitos binucleados, así como un mayor mantenimiento de la polaridad; sin embargo, algunas muestras evidenciaron microvacuolas y leve fragmentación de la cromatina. Conclusión: La harina de camu camu evidenció efecto hepatoprotector frente a la toxicidad por acetaminofén en ratones.

Palabras clave: Plantas Medicinales; Estrés Oxidativo; Ratones; Acetaminofén; Higado (Fuente: DeCS BIREME).

Abstract

Objectives. To evaluate the effect of Myrciaria dubia (camu camu) flour on liver tissue induced to acetaminophen toxicity in mice. Methods. Experimental design. A suspension of camu camu flour (HCC) with $1.6 \%$ starch was prepared. 40 male mice of the BALB/c strain were used, with an average weight of 30.8 $\mathrm{g}$ and two months of age, which were divided into five groups, receiving the following treatment, orogastric route, for a period of 10 days, groups I and II: $1.6 \%$ starch $10 \mathrm{~mL} / \mathrm{kg}$; group III: HCC $200 \mathrm{mg} / \mathrm{kg}$, group IV: HCC $500 \mathrm{mg} / \mathrm{kg}$ and group V: HCC $800 \mathrm{mg} / \mathrm{kg}$. On the 6th day of treatment, acetaminophen $(300 \mathrm{mg} / \mathrm{kg})$ was administered to groups II-V until the 10th day. After the intervention, the animals were fasted for 12 hours, to then be sacrificed after anesthesia with sodium pentobarbital. The liver was removed, the greater lobe was identified and sectioned for biochemical and histological study. Results. The camu camu flour reduced the levels of the hepatic index, and presented a better profile of the glutathione system, compared to group II; however, the lipoperoxidation figures did not show a significant difference. At the histological level, in the groups that received HCC, binucleated hepatocytes were observed, as well as a greater maintenance of polarity; however, some samples showed microvacuoles and slight chromatin fragmentation. Conclusion: Camu camu flour showed a hepatoprotective effect against acetaminophen toxicity in mice.

Keywords: Plants, Medicinal; Oxidative Stress; Mice; Acetaminophen; Liver (source: MeSH NLM). 


\section{INTRODUCCIÓN}

Las enfermedades del hígado representan una alta carga de morbimortalidad en el mundo. Según la OMS, para el año 2019 estas enfermedades se encontraban entre las diez primeras causas de decesos en países de bajos ingresos ${ }^{(1)}$. Dentro de las etiologías más frecuentes están aquellas relacionadas a la alteración del metabolismo, tales como la esteatosis hepática no alcohólica (EHNA), virales crónicas como la hepatitis $\mathrm{B}$, y el consumo crónico de alcohol ${ }^{(2)}$.

Se ha observado que radicales libres $(\mathrm{RL})$ participan en el desarrollo de la inflamación, cirrosis y diversas lesiones del hígado, produciendo lipoperoxidación a nivel celular o disminución de la actividad de las enzimas con capacidad antioxidante ${ }^{(3)}$. Para contrarrestar los efectos de estos $\mathrm{RL}$, se requiere de sustancias denominadas antioxidantes, las cuales se encuentran en ciertos alimentos. Estas sustancias atenúan los efectos dañinos de los RL, actuando como agentes reductores o induciendo la expresión de sistemas antioxidantes celulares. En el grupo de los antioxidantes exógenos, se encuentran los carotenoides, flavonoides, vitamina $E$, vitamina $C$, entre otros ${ }^{(4,5)}$.

Se ha evaluado la capacidad protectora del camu camu en diversos estudios, tal es el caso de una investigación realizada en Japón, en donde se les proporcionó a varones fumadores con cuadro de estrés progresivo, jugo de camu camu (1050 mg de vitamina C) de forma diaria, por un período de siete días, reduciendo los marcadores oxidativos, como la proteína $C$ reactiva e interleucinas 6 y $8^{(6)}$

Un estudio realizado en animales de experimentación, evidenció el posible efecto nefroprotector de la Myrciaria dubia frente al daño nefrotóxico inducido por gentamicina. Los resultados indicaron protección a distintas dosis del extracto alcohólico del fruto, tanto en el estudio histopatológico mediante una menor pérdida epitelial, inflamación y congestión vascular, como a nivel sérico con una disminución de la concentración de creatinina sérica frente al grupo inducido sólo al daño ${ }^{(7)}$.

De igual manera, se ha demostrado su capacidad antioxidante observándose que la Myrciaria dubia inhibe el daño en el ADN frente a un modelo oxidativo ocasionado por $\mathrm{KBrO}_{3}$ en un estudio in vitro. Estos efectos fueron atribuidos al ácido ascórbico y los flavonoides, compuestos funcionales del fruto ${ }^{(8)}$

La Myrciaria dubia es oriunda de la amazonia peruana, su fruto presenta un alto contenido de vitamina $\mathrm{C}$ y otros compuestos bioactivos (antocianinas, catequinas, flavonoides), relacionados con un efecto protector y antioxidante en anteriores estudios. Estos componentes le han atribuido una variedad de efectos protectores a la salud, relacionándolo con un efecto antimutagénico, antioxidante e hipolipemiante ${ }^{(9)}$.

El presente estudio tuvo por objetivo evaluar el efecto de la harina de Myrciaria dubia (camu camu) sobre el tejido hepático inducido a toxicidad por acetaminofén en ratones.

\section{MÉTODOS}

\section{Diseño de investigación}

Se realizó un estudio experimental, con grupo control.

\section{Suspensión de harina de camu camu}

La harina de camu camu ( $\mathrm{HCC}$ ) se adquirió de la empresa Agroindustrial del Perú S.A. Para darle estabilidad, la HCC fue suspendida en un medio coloidal (MC) de almidón al 1,6\%.

\section{Ensayo del efecto hepatoprotector}

Se utilizaron 40 ratones albinos machos (BALB/C), de 2 meses de edad, con peso promedio de $30,8 \mathrm{~g} \pm 5,1 \mathrm{~g}$ adquiridos del Instituto Nacional de Salud, mantenidos por un periodo de aclimatación de siete días, con dieta balanceada, agua ad libitum, y con fotoperiodo (12 horas de luz y 12 horas de oscuridad) en el bioterio de la Facultad de Medicina de la Universidad Nacional Mayor de San Mar$\cos$ (UNMSM).

Para inducir al daño hepático se utilizó la propuesta modificada de Gibson y col. (10), que consiste en la administración, vía orogástrica, de acetaminofén (300 mg/kg).
Tras el periodo de aclimatación, fueron distribuidos en cinco grupos $(n=8)$, recibiendo por 10 días los siguientes tratamientos, vía orogástrica:

Grupo I: MC $10 \mathrm{~mL} / \mathrm{kg}$

Grupo II: MC $10 \mathrm{~mL} / \mathrm{kg}$

Grupo III: HCC 200 mg/kg

Grupo IV: HCC 500 mg/kg

Grupo V: HCC 800 mg/kg

Al sexto día de iniciado el tratamiento, a los grupos II-V se les administró 300 $\mathrm{mg} / \mathrm{kg}$ de acetaminofén, vía orogástrica, hasta el día diez. Terminado el período de tratamiento, los ratones fueron sometidos a 12 horas de ayuno, posteriormente fueron anestesiados con pentobarbital, vía intraperitoneal, y se realizó laparotomía para extraer el hígado el cual fue lavado con solución salina isotónica y pesado (Radwag WTB 200). Del lóbulo mayor se seccionaron dos porciones, para los indicadores bioquímicos y para el estudio histológico.

Determinación de los indicadores morfológicos

- Homogenizado de tejido hepático (Hmg): se homogenizó aproximadamente 0,2 g de tejido hepático con buffer fosfato $(0,01 \mathrm{~mol} / \mathrm{L} \mathrm{a} \mathrm{pH} 7,4)$, a volumen final de $2 \mathrm{~mL}$.

- Determinación de la lipoperoxidación: (método de Buege y Aust) ${ }^{(11)}$. Se utilizó 0,5 mL de Hmg y se agregó $1 \mathrm{~mL}$ de ácido tricloroacético 20\% (TCA) (JT BAKER), luego se colocó por 10 minutos en baño María hirviente $\left(100^{\circ} \mathrm{C}\right)$. Posteriormente, fue retirado y enfriado, y se adicionó $1,5 \mathrm{~mL}$ de ácido 2-tiobarbitúrico (SIGMA) a $0,67 \%$ en $\mathrm{HCl} 0,25 \mathrm{~N}$, volviéndose a colocar por 20 minutos en baño María hirviente. Concluida la incubación, fue centrifugado por 15 minutos a 3500 rpm y leído en espectrofotómetro a $535 \mathrm{~nm}$.

- Determinación del GSH: (método de Seldak y Lindsay, con adaptación) (12). Del Hmg se tomó $1 \mathrm{~mL}$ y se agregaron $0,4 \mathrm{~mL}$ de TCA al 50\% con 0,8 mL de agua bidestilada, y se agitó por dos minutos. Luego fue centrifugado por 15 minutos a $4000 \mathrm{rpm}$, obteniéndose el sobrenadante del desproteinizado (SNDP). 
Se tomó 0,5 mL del SNDP y se agregó $2 \mathrm{~mL}$ de TRISMA buffer (SIGMA) $\mathrm{pH}$ 8,9 a $0,4 \mathrm{~mol} / \mathrm{L}$, inmediatamente se incubó a $60^{\circ} \mathrm{C}$ por 5 minutos. Concluida la incubación fue retirado y se dejó enfriar para luego agregar $25 \mu \mathrm{L}$ de ácido 5,5'-ditiobis-2-nitrobenzoico (DTNB) (SIGMA) 0,01 mol/L. Posteriormente se leyó a $412 \mathrm{~nm}$.

- Determinación de glutatión total: se siguió el mismo protocolo para la determinación del GSH, empleando un buffer TRISMA (15 mL de buffer + 7,5 mg de ácido glioxílico + $15 \mathrm{mg}$ de ácido ascórbico) 0,4 mol/L, pH 8,9.

Evaluación morfológica e histológica, y determinación del índice hepático

El tejido extraído se conservó en formol al 10\% tamponado (buffer fosfato $\mathrm{pH}$ $7,4$ a $0,075 \mathrm{~mol} / \mathrm{L})$, los cuales fueron fijados en parafina y teñido con hematoxilinaeosina, en el Instituto de Patología de la UNMSM, y leído por un patólogo. Para el análisis de las muestras se consideró los siguientes aspectos: espacio portal, estructura del lobulillo hepático, conductos biliares, células de Kupffer y aspecto de los hepatocitos. Para determinar el índice hepático se empleó el peso del hígado y del animal, expresado en porcentaje.

\section{Análisis estadístico y aspectos éticos}

Para evaluar la normalidad de los datos se aplicó Shapiro-Wilk. Para aquellos indicadores que presentaron distribución normal se aplicó ANOVA, luego el estadístico de Levene para evaluar la homogeneidad de varianzas y por último el estadístico de Tukey.

El presente estudio consideró las normas éticas de experimentación animal según Pardo ${ }^{(13)}$ y lo dispuesto por la Ley de Protección y Bienestar Animal N $30407^{(14)}$.

\section{RESULTADOS}

Respecto a lo observado en el grupo II, sobre los indicadores de estrés oxidativo, tras la administración del acetaminofén, el nivel de lipoperoxidación fue mayor (tabla 1); sin embargo, también presentó mayor nivel de GSH (Figura 1) y glutatión oxidado (GSSG) (Figura 2) sin mostrar di-
Tabla 1. Nivel de índice hepático y lipoperoxidación por grupo de tratamiento, en ratones, para la determinación del efecto de harina de Myrciaria dubia en el daño hepático inducido por acetaminofén

\begin{tabular}{llccc} 
Grupo & Tratamiento & \multicolumn{2}{c}{ Índice hepático* (\%) } & $\begin{array}{c}\text { Lipoperoxidación* } \\
\text { (mmol/g de tejido) } \\
\text { Media } \pm \text { DE }\end{array}$ \\
\cline { 3 - 5 } Grupo I & MC $10 \mathrm{~mL} / \mathrm{kg}$ & $4,7 \pm 0,6^{\mathrm{a}}$ & -- & $25,4 \pm 2,3$ \\
\hline Grupo II & MC $10 \mathrm{~mL} / \mathrm{kg}$ & $5,2 \pm 0,3$ & -- & $28,1 \pm 2,6$ \\
\hline Grupo III & HCC $200 \mathrm{mg} / \mathrm{kg}$ & $4,9 \pm 0,2$ & 6,7 & $33,0 \pm 2,6^{\mathrm{a}}$ \\
\hline Grupo IV & HCC $500 \mathrm{mg} / \mathrm{kg}$ & $4,8 \pm 0,4^{\mathrm{a}}$ & 8,8 & $30,2 \pm 3,0$ \\
\hline Grupo V & HCC $800 \mathrm{mg} / \mathrm{kg}$ & $4,6 \pm 0,4^{\mathrm{b}}$ & 11,1 & $29,7 \pm 4,2$ \\
\hline
\end{tabular}

*Shapiro-Wilk ( $p>0,05)$ - ANOVA- Levene- Tukey

MC: medio coloidal de almidón

HCC: harina de camu camu

a $p<0,05$ respecto al grupo $\|$

${ }^{\mathrm{b}} \mathrm{p}<0,01$ respecto al grupo II ferencia significativa, respecto al grupo I. Los grupos que recibieron HCC, a diferentes dosis, mostraron niveles más altos de la relación GSH/GSSG (Figura 2), respecto al grupo II, siendo significativos en los grupos IV y $\vee(p<0,05)$.

En relación a los índices morfológicos, en los ratones que solo recibieron acetaminofén (grupo II), se observó una mayor masa hepática, respecto al grupo I $(p<0,05)$ (Tabla 1$)$, y a nivel de la histoarquitectura se evidenció retención hemática y congestión sinusoidal de forma muy marcada; además, se apreció lisis de hepatocitos y cromatina fragmentada en la mayoría de los cortes. También se visualizó una pérdida de la distribución polar de los hepatocitos, infiltración linfomonocitaria perivascular y hepatocitos anucleados, presentando heterogeneidad y disparidad en todas las muestras evaluadas, en comparación al grupo I, el cual presentó una estructura conservada (Figura 3).

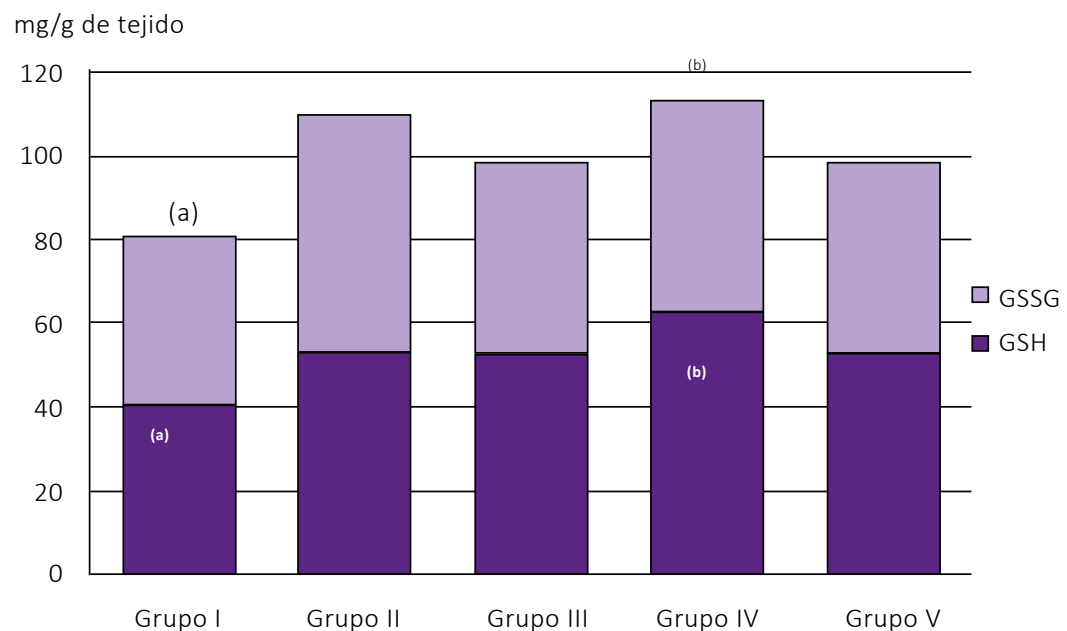

Figura 1. Glutatión (GSH) y glutatión oxidado (GSSG) en tejido hepático, según grupo de tratamiento, en la evaluación del efecto de la harina de Myrciaria dubia en el daño hepático inducido por acetaminofén

Shapiro-Wilk ( $p>0,05)$ - ANOVA- Levene-Tukey

(a) $p<0,01$ respecto al grupo II

(b) $p<0,05$ respecto al grupo II 
1,3

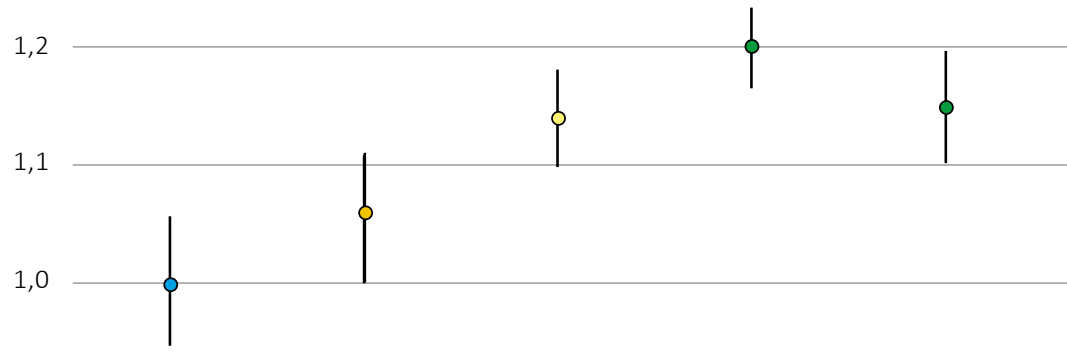

0,9

G-I

G-II

G-III

G-IV

G-V

Figura 2. Relación glutation/glutation oxidado (GSH/GSSG) en tejido hepático según grupo de tratamiento, en la evaluación del efecto de la harina de Myrciaria dubia en el daño hepático inducido por acetaminofén

Shapiro-Wilk ( $p>0,05)$ - ANOVA- Levene- Tukey

(a) $p<0,01$ respecto al grupo II

(b) $p<0,05$ respecto al grupo II

Los grupos que recibieron las diferentes dosis de HCC más acetaminofén, mostraron una disminución de su masa hepática dosis dependiente, siendo significativos en los grupos IV y $\mathrm{V}$, comparado con el grupo II. Respecto al aspecto histológico, el grupo III (HCC 200 mg/kg) solo una muestra presentó canales biliares pignóticos, dos muestras presentaron localización de edema lobulillar y citoplasma vacuolado. También se observó leve congestión vascular (Figura 3, grupo III). El grupo IV (HCC 500 $\mathrm{mg} / \mathrm{kg}$ ) presentó una leve fragmentación de cromatina y mantenimiento polar de los hepatocitos, sin mayor daño (Figura 3, grupo IV); el grupo V (HCC 800 mg/ $\mathrm{kg}$ ) mostró un mantenimiento ligero de la polaridad hepática, con espacio de Disse dilatado, también se observó en algunas muestras microvacuolas (Figura 3, grupo V). Todos los grupos que recibieron HCC presentaron binucleación de hepatocitos esparcidos en el tejido.

\section{DISCUSIÓN}

Los alimentos contienen compuestos que reducen los efectos nocivos de sustancias como los RL sobre las estructuras y funciones fisiológicas ${ }^{(15)}$. Hoy en día se conoce el papel de los antioxidantes como protector en múltiples enfermedades, entre ellas el cáncer, enfermedades cardiovasculares, enfermedades hepá- ticas, diabetes mellitus, enfermedades neurodegenerativas (Alzheimer y Parkinson), entre otros ${ }^{(16,17)}$

Según nuestros hallazgos, lo observado en el grupo II se encuentra relacionado a la sobredosis de acetaminofén, que en su metabolismo ocasiona la activación de factores proinflamatorios como el factor de transcripción nuclear KB (NF-KB) $y$ el factor de necrosis tumoral (TNF- $\alpha$ ), este último induce una cascada de citoquinas (IL-6, IL-8, IL-1ß), desencadenando una respuesta inflamatoria, que va acompañada con necrosis tisular $(18,19)$ Las lesiones hepatocelulares inducen a la inflamación con grados variables (hepatomegalia) y con predominio de necrosis centrolobulillar; también se presenta vacuolización de los hepatocitos centrilobulillares, traduciéndose en una delimitación de esta zona e infiltración de leucocitos ${ }^{(20,21)}$, tal como se observó en el grupo II.

La biotransformación del acetaminofén por el citocromo $\mathrm{P} 450$, produce $\mathrm{N}$-acetil $\mathrm{p}$ benzoquinonaimina (NAPQI), que se une a las proteínas mitocondriales induciendo a estrés oxidativo, el cual genera radicales libres de oxígeno (ROS); esto podría estar relacionado con un mayor nivel de lipoperoxidación en el grupo II. EI NAPQI también disminuye los niveles de GSH; sin embargo, pasadas las 48 horas, los niveles de GSH se pueden recuperar en un $70 \%$, surgiendo una respuesta frente al continuo estrés oxidante ${ }^{(22,23,24)}$.

Diversos autores han descrito la toxicidad del acetaminofén; así, Troncoso, empleando acetaminofén (200 mg/kg) en ratas, reportó a nivel histológico, hipertrofia de células de Kupffer, necrosis severa y retención biliar ${ }^{(25)}$. En otro estudio, empleando $300 \mathrm{mg} / \mathrm{kg}$ de acetaminofén en ratones, se encontró alteración de la estructura hepática, congestión parenquimal, incremento de las células de Kupffer y apoptosis ${ }^{(26)}$.

Los efectos benéficos encontrados en los grupos con ingesta de HCC, frente a la toxicidad del acetaminofén, pueden estar relacionados a las propiedades del ácido ascórbico (AA) en el control de los procesos de autofagia inducidos por los ROS y un sistema cisteína/cistina disminuida por el proceso metabólico tóxico del acetaminofén. El sistema cisteína/cistina es importante en la síntesis de GSH ${ }^{(27)}$. El AA se encuentra en alta concentración en el camu camu, y su efecto podría estar relacionado con los niveles de GSH/GSSG en los grupos III-V (Figura 2).

Dentro de los compuestos fenólicos en el camu camu se encuentran los flavonoides, los cuales interactúan con los radicales libres evitando el daño oxidativo de los ácidos grasos poliinsaturados, limitando de esta manera el proceso de peroxidación lipídica, que es una característica del daño hepatocelular. Los efectos antioxidantes de estas sustancias ya han sido reportados por Nasser, quien tras administrar Egyptian Vicia calcarata y $\mathrm{CCl}_{4}$, redujo los niveles de malondialdehido, el cual es un indicador de la lipoperoxidación, e indujo las actividades de GSH peroxidasa, glucosa 6-P deshidrogenasa, superóxido dismutasa y catalasa, y de los niveles de GSH; dicho autor atribuyó estos efectos a los flavonoides, entre ellos el kaempferol y la quercetina (28). Esto podría estar relacionado a un probable efecto protector del camu camu, que dentro de su composición de flavonoides se encuentran la quercetina, miricetina, y otros polifenoles como el ácido siríngico y el ácido elágico ${ }^{(29)}$.

El efecto que ejerce la quercetina sobre la lesión hepática se relaciona con una disminución de las actividades de las transaminasas (ALT y AST), TNF- $\alpha$ y múltiples citoquinas que están asociadas a la inflamación, fibrosis y necrosis hepática. También se le relaciona con un aumento de GSH y de IL-10, este último actúa como un potente antiinflamatorio ${ }^{(30)}$. 


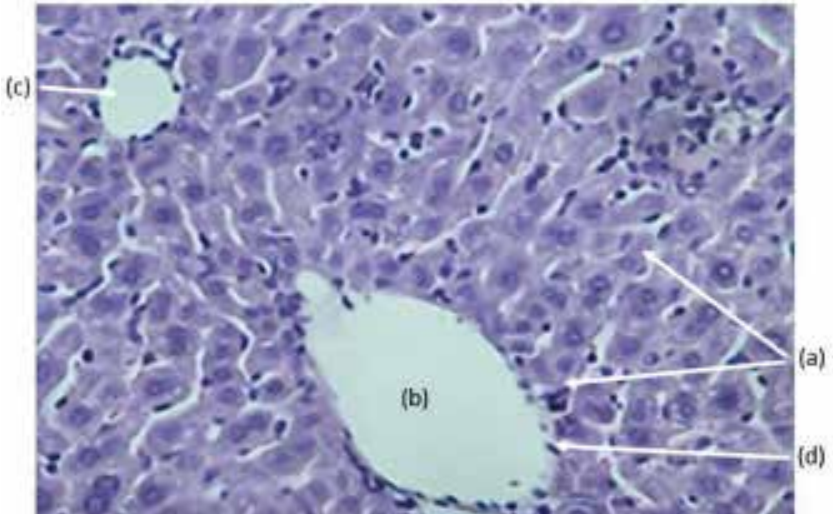

Grupo I. Sin tratamiento (tejido hepático). No existen signos de daño tisular. (a) Hepatocitos ordenados y preservados, (b) Vena porta, (c) Conducto biliar (d) Células de Kupffer. Hematoxilina-eosina HE, 40x.

(c)

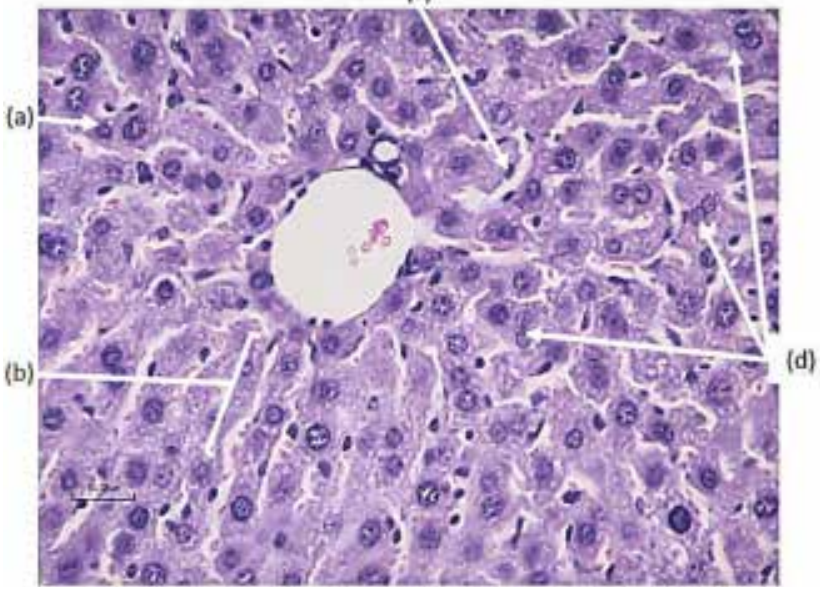

Grupo III. Myrciaria dubia $200 \mathrm{mg} / \mathrm{kg}$ + acetaminofén (tejido hepático). (a) Congestión vascular, b) Hepatocitos binucleados como signo de regeneración, c) Membrana del núcleo de los hepatocitos ligeramente engrosada, d) Condensación de la cromatina. HE, 40x.

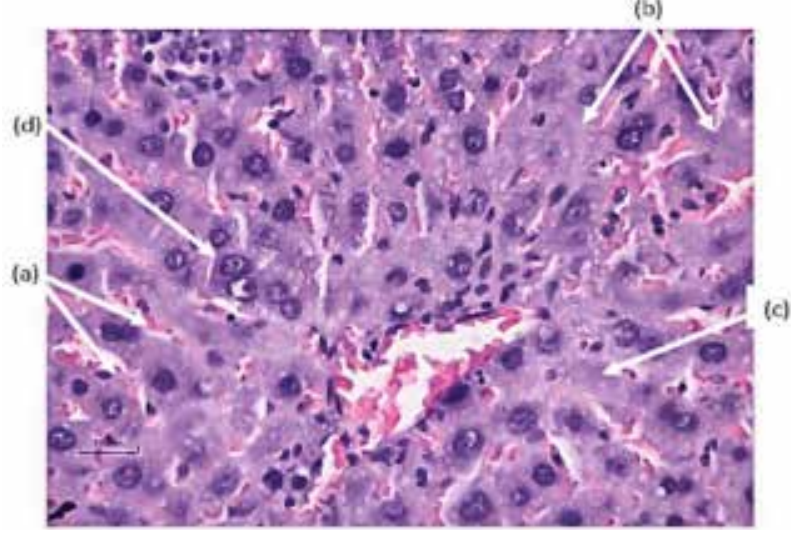

Grupo II. Acetaminofén (tejido hepático). (a) Congestión sinusoidal, (b) Lisis de hepatocitos, (c) Pérdida de núcleo de los hepatocitos (d) Fragmentación de la cromatina. (e) Infiltración linfomonocitaria perivascular. $\mathrm{HE}, 40 \mathrm{x}$.

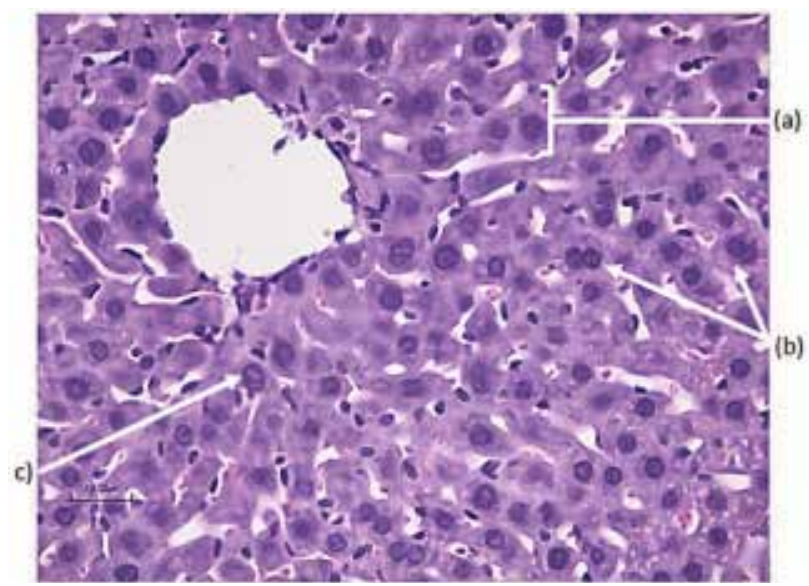

Grupo IV. Myrciaria dubia $500 \mathrm{mg} / \mathrm{kg}+$ acetaminofén (tejido hepático). (a) Mantenimiento de la polaridad de los hepatocitos, (b) Hepatocitos binucleados como signo de regeneración, (c) Fragmentación de la cromatina. HE, 40x.

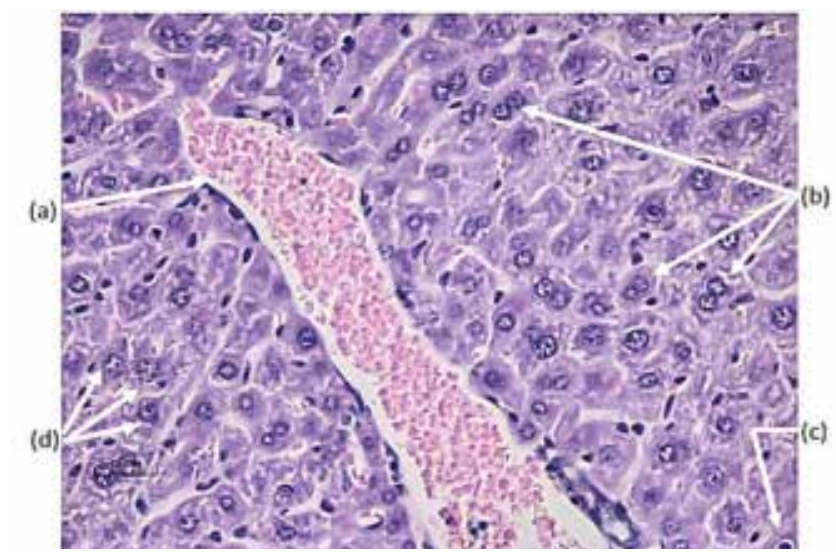

Grupo V. Myrciaria dubia 800 mg/kg + acetaminofén (tejido hepático). (a) Membrana citoplasmática casi intacta, (b) Mantenimiento de la polaridad hepática (c) Espacio de Disse ligeramente dilatados, (d) Hepatocitos binucleados como signo de regeneración. HE, 40x.

Figura 3. Microfografías de los grupos de ratones I al V. Efecto de la harina de Myrciaria dubia en el daño hepático inducido por acetaminofén. 
Las catequinas, presente en la HCC, han sido evaluadas frente a la hepatotoxicidad por fármacos, observándose un menor daño a nivel histológico y una menor actividad de las transaminasas en sangre. También se observó una menor actividad de CYP3A y CYP2E1, enzimas que metabolizan al acetaminofén ${ }^{(31)}$. Esto podría estar relacionado a lo observado en nuestro estudio, en los grupos que recibieron $\mathrm{HCC}$ en las diferentes dosis a nivel histológico y del perfil de GSH.

La presencia de binucleación de hepatocitos en los grupos que recibieron la HCC, podría estar relacionado al GSH, a nivel nuclear, ya que este antioxidante promueve la replicación, reparación y expresión del ADN, como también participa en el control de la mitosis ${ }^{(32)}$. Otro aspecto importante es la relación GSH/ GSSG, ya que es un indicador del estado redox del tejido hepático, por tanto, un incremento de GSH, ligado a compuestos bioactivos, podrían jugar un papel en la regeneración del tejido ${ }^{(33)}$.

El presente estudio no evaluó transaminasas a nivel sérico, debido a la dificultad de la obtención de muestra de sangre. Otra limitación fue la no determinación de grupos sulfhidrilos proteicos, por carencia de reactivo.

Concluimos, según nuestros hallazgos, que la administración de harina de Myrciaria dubia (camu camu) presenta efecto hepatoprotector frente al acetaminofén, evidenciado en el tamaño de la masa hepática, en la histoarquitectura e indicadores bioquímicos, en ratones.

\section{AGRADECIMIENTOS}

Al Dr. Felio Palomino, médico patólogo, por la evaluación de los cortes histológicos.

\section{REFERENCIAS BIBLIOGRÁFICAS}

1. Organización Mundial de la Salud [Internet]. Las 10 principales causas de defunción. OMS, 2019 [citado el 10 Junio 2021]. Disponible en: https:// www.who.int/es/news-room/fact-sheets/detail/ the-top-10-causes-of-death

2. Coronel ME, Coronel CM. Esteatohepatitis no alcohólica (EHNA). Rev Gastroenterol Peru. 2016;36(1):58-65.
3. Sánchez-Valle V, Méndez-Sánchez N. Estrés oxidativo, antioxidantes y enfermedad. Rev Invest Med Sur Mex. 2013; 20(3): 161- 168.

4. Raza S, Tewari A, Rajak S, Sinha R. Vitamins and non-alcoholic fatty liver disease: A molecular insight. Liver Res, 2021. DOI: https://doi. org/10.1016/j.livres.2021.03.004

5. Ferney J, Amador G, Restrepo J. Tratamiento con vitamina $E$ en pacientes con esteatohepatitis no alcohólica.Rev Col Gastroenterol. 2014;29(4). DOI: https://doi.org/10.22516/25007440.437

6. Inoue T, Komoda H, Uchida, T Node, K. Tropical fruit camu-camu (Myrciaria dubia) has anti-oxidative and anti-inflammatory properties. J Cardiol. 2008;52(2):127-32. DOI: 10.1016/j. jjcc.2008.06.004

7. Becerra K, García J, Becerra M, Ruiz E, Chávez L. Efecto nefroprotector del Camu Camu (Myrciaria dubia) en un modelo de nefrotoxicidad inducida por gentamicina en ratas. Rev Chil Nutr. 2019; 46(3): 303-307. DOI: http://dx.doi.org/10.4067/ S0717-75182019000300303

8. Alvis R, Pino J, Gonzáles J, Francia J, Shiga B Efecto citoprotector del camu-camu Myrciaria dubia en tres líneas celulares de ratón expuestos in vivo a bromato de potasio. Rev. peru biol. 2010;17(3): 389-392.

9. Langley P, Pergolizzi J, Taylor R, Ridgway C Antioxidant and Associated Capacities of Camu Camu (Myrciaria dubia): A Systematic Review. J Altern Complement Med. 2015; 21(1): 8-14. DOI: 10.1089/acm.2014.0130

10. Gibson JD, Pumford NR, Samokyszyn VM, Hinson JA. Mechanism of acetaminophen-induced hepatotoxicity: covalent binding versus oxidative stress. Chem Res Toxicol. 1996;9(3):580-5. DOI: 10.1021/tx950153d

11. Buege J, Aust S. Microsomal lipid peroxidation. Methods Enzymology. 1978;52:302-36. DOI: 10.1016 / s0076-6879 (78) 52032-6

12. Sedlak J, Lindsay R. Estimation of total, proteinbound, and nonprotein sulfhydryl groups in tissue with Ellman's reagen. Rev Analytical Biochemistry.1968;25:192-205. DOI: 10.1016/0003-2697 (68) 90092-4

13. Pardo C. Ética de la experimentación animal directrices legales y ética contemporáneas. Departamento de humanidades biomédicas, 3ra edición. Universidad de Navarra, 2005

14. El Peruano [Internet]. Ley $N^{\circ}$ 30407. Ley de Protección y Bienestar Animal. 2016 [citado el 10 Junio 2021]. Disponible en: https://busquedas. elperuano.pe/normaslegales/ley-de-proteccion-ybienestar-animal-ley-n-30407-1331474-1/

15. Manal A, Abdulkareem S, Abeer A. Antioxidant Categories and Mode of Action. IntechOpen. 2019. DOI: 10.5772/intechopen.83544

16. Hyungsun $\mathrm{P}$, Jongyoon K, Chihoon S, Seongju L. Intersection between Redox Homeostasis and Autophagy: Valuable Insights into Neurodegeneration. Antioxidants. 2021;10(5):694. DOI: https:// doi.org/10.3390/antiox10050694

17. Sila A, Mustafa C, Ozgun T, Adnan A. Dietary Antioxidants in Experimental Models of Liver Diseases. IntechOpen. 2019. DOI: 10.5772/intechopen.83485

18. Devkar S, Kandhare A, Zanwar A, Jagtap S, Katyare S, Bodhankar S, et al. Hepatoprotective effect of withanolide-rich fraction in acetaminophen-intoxicated rat: decisive role of TNF- $\alpha$, IL-1 $\beta$, COX-I and iNOS. Pharmaceutical Biology. 2016; 54(11), 2394-2403. DOI: 10.3109/13880209.2016.1157193
19. Xing-Yue $X$, Wang Z, Shen R, Leng J, Hu J, Zhi $\mathrm{L}$, et al. Improved protective effects of American Ginseng Berry against Acetaminophen-induced liver toxicity through TNF-mediated caspase-3/-8/-9 signaling pathways. Phytomedicine. 2018;51:128138. DOI: $10.1016 /$.j.phymed.2018.09.234

20. Krishna. Patterns of necrosis in liver disease. Clin Liver Dis (Hoboken). 2017;10(2):53-56. DOI: 10.1002/cld.653

21. Yoon E, Babar A, Choudhary M, Kutner M, Pyrsopoulos N. Acetaminophen-Induced Hepatotoxicity: a Comprehensive Update. J Clin Transl Hepatol. 2016;4(2):131-142. DOI: 10.14218/ JCTH.2015.00052

22. Butler D, Lewin D, Batalis N. Differential Diagnosis of Hepatic Necrosis Encountered at Autopsy. Acad Forensic Pathol. 2018; 8(2): 256-295. DOI: $10.1177 / 1925362118782056$

23. Woolbright $B$, Jaeschke $H$. Mechanisms of Inflammatory Liver Injury and DrugInduced Hepatotoxicity. Current Pharmacology Reports. 2018;4:346-357. DOI: 10.1007/s40495-018-0147-0

24. Saito C, Zwingmann C, Jaeschke H. Novel mechanisms of protection against acetaminophen hepatotoxicity in mice by glutathione and $\mathrm{N}$-acetylcysteine. Hepatology. 2010;51(1):246-254. DOI: 10.1002/hep.23267

25. Troncoso L, Guija E. Efecto antioxidante y hepatoprotector del Petroselinum sativum (perejil) en ratas, con intoxicación hepática inducida por acetaminofén. An Fac Med Lima 2007; 68(4): 333-343.

26. Hilario G, Mejía P. Efecto hepatoprotector del zumo de cogollo de Cynara scolymus (corazón de alcachofa) en ratones sometidos a intoxicación por paracetamo (Tesis para obtener el título de licenciado en nutrición y dietética). Lima, Perú: Universidad Católica Sedes Sapientiae, 2016.

27. Kurahashi T, Nabeshima A, Homma E, Saito Y, Yamada S, Nakayama T, et al. Ascorbic acid prevents acetaminophen-induced hepatotoxicity in mice by ameliorating glutathione recovery and autophagy. Archives of Biochemistry and Biophysics. 2016;604:36-46. DOI: 10.1016/j.abb.2016.06.004

28. Singab AN, Youssef DT, Noamn E, Kotb S. Hepatoprotective Effect of Flavonol Glycosides Rich Fraction from Egyptian Vicia calcarata Desf. Against CCl4- Induced Liver Damage in Rats. Arch Pharm Res. 2005;28(7): 791-8. DOI: 10.1007/BF02977344

29. Arellano E, Rojas I, Paucar L. Camu-camu (Myrciaria dubia): Fruta tropical de excelentes propiedades funcionales que ayudan a mejorar la calidad de vida. Scientia Agropecuaria. 2016;7(4):433443. DOI: http://dx.doi.org/10.17268/sci.agropecu.2016.04.08

30. Chen X. Protective effects of quercetin on liver injury induced by etanol. Pharmacognosy Magazine. 2010;6(22):135-141. DOI: 10.4103/09731296.62900

31. Yao HT, Yang $Y$, Yang $H$, Yin M. Protective effects of (-)-epigallocatechin-3-gallate against acetaminophen induced liver injury in rats. Biomedicine. 2015;5(3):15. DOI: 10.7603/s40681-015-0015-8

32. Garcia J, Markovic J, Dasi F, Queval G, Schanaubelt D, Foyer C, et al. Nuclear glutathione. Biochimica et Biophysica Acta. 2013; 1830 (5):3304-3316. DOI: 10.1016/j.bbagen.2012.10.005

33. Vairetti M, Di Pasqua L, Cagna M, Richelmi $P$, Ferrigno A, Berardo C. Changes in Glutathione Content in Liver Diseases: An Update. Antioxidants. 2021; 10(3): 364. DOI: https://doi.org/10.3390/ antiox 10030364 